\title{
Translational aspects of body image research for obesity-related quality of life and weight loss maintenance post-bariatric surgery
}

\author{
Marie L. Caltabiano \\ Psychology, College of Healthcare Sciences, Division of Tropical Health \& Medicine, James Cook University, Cairns, QLD, Australia \\ Correspondence to: Associate Professor Marie L. Caltabiano. Psychology, College of Healthcare Sciences, Division of Tropical Health \& Medicine, \\ James Cook University, McGregor Road, Cairns 4878, QLD, Australia. Email: marie.caltabiano@jcu.edu.au.
}

\begin{abstract}
Background: The Aim of the study was to examine obesity health-related quality of life and body image satisfaction in a group of individuals having undergone bariatric surgery.

Methods: One hundred and forty-two persons who had undergone bariatric surgery answered an online survey which included measures of well-being and body image. The Multidimensional Body Self-Relations Questionnaire-Appearance Scales (MBSRQ-AS 34) was used to assess body image in relation to appearance evaluation (AE), appearance orientation (AO), overweight preoccupation (OP), self-classified weight (SCW), and body areas satisfaction (BASS). Obesity-related quality of life was assessed with the obesity related wellbeing scale (Orwell 97).

Results: Hierarchical multiple regression indicated that $50.2 \%$ of the variance in well-being postsurgery was explained by body image variables $[F(6,84)=18.54, \mathrm{P}<0.01]$, with the strongest predictor being satisfaction with body areas $(B=-0.360, \mathrm{P}<0.01)$. Regression analysis of the data for the group of patients who had received the vertical sleeve surgery was also significant, $[F(6,56)=10.16, \mathrm{P}<0.001]$ with satisfaction with different body areas being the best predictor of well-being $(B=-0.365, \mathrm{P}<0.05)$, followed by OP $(B=0.313$, $\mathrm{P}<0.05)$ and SCW $(B=0.281, \mathrm{P}<0.05)$.

Conclusions: Body image concerns are more important predictors for well-being post bariatric surgery than weight lost. Psychological factors such as the perception of body areas, continued weight preoccupation and SCW rather an objective weight were better predictors of well-being, symptoms that impacted on wellbeing and on the subjective relevance of the symptoms to well-being. Recommendations for the translation of the present research findings for the surgical preparation of the bariatric patient and for post-surgery care are suggested.
\end{abstract}

Keywords: Bariatric surgery; body image; weight lost; obesity-related well-being

Submitted May 27, 2019. Accepted for publication Sep 09, 2019.

doi: $10.21037 /$ atm.2019.09.63

View this article at: http://dx.doi.org/10.21037/atm.2019.09.63

\section{Introduction}

\section{Translational research}

Most research in clinical health psychology has an applied focus. Translational and implementation research has as its central objective the improvement of clinical practice founded on evidence-based research. Titler (1) defined translational research as

"The scientific investigation of methods and variables that affect adoption of evidenced based health care practices by individual practitioners and health care systems to improve clinical and operational decision-making" (p. 38).

Obesity or the excessive accumulation of body fat, is defined as having a body mass index (BMI) over $30 \mathrm{~kg} / \mathrm{m}^{2}$. In Australia, $63 \%$ of adults are overweight or obese (2).

Bariatric surgery refers to the group of surgical interventions applied for weight loss. There are four types of bariatric surgery: laparoscopic adjustable gastric banding (LAGB), laparoscopic vertical sleeve gastrectomy (LVSG), laparoscopic Roux-en-Y gastric bypass (LRYGB), 
and laparoscopic duodenal switch with biliopancreatic diversion (3). Weight loss is achieved through these interventions by various methods of stomach reduction that in turn reduce hunger drive and the individual's ability to consume large portions of food. In 2014-2015, 22,700 weight loss surgeries were performed in Australia (3).

Bariatric surgery effectively treats all biological conditions of the metabolic syndrome (hypertension, high insulin levels, high levels of adipose tissue in the midsection and abnormal cholesterol levels), with patients having diabetes in remission or significantly reduced diabetes 12 months after surgery (4-6). While bariatric surgery, is indicated to produce rapid and sustained weight loss results for approximately 18-24 months post-surgery, longitudinal studies have reported mixed findings on whether weight loss is sustained, regardless of the type of surgery (7-13).

The current research is concerned with obesity surgery outcomes in relation to weight loss maintenance; perceived body image and well-being of patients. Basic research in medicine $(14,15)$ and in psychology $(16,17)$ has identified the biopsychosocial factors which contribute to obesity. Health outcomes for the bariatric patient are not only influenced by biological mechanisms but also by psychological factors. This paper considers translational aspects of body image research for post-bariatric clinical practice.

\section{Bariatric surgery and quality of life (QoL)}

QoL is an individual's subjective assessment of their capacity in relation to the physical, emotional, material and social well-being domains of their life (18). The World Health Organization (19) further quantifies measurement of health-related QoL (HRQoL) as the distance between the patient's present overall state in the physical, psychological, independence, social, environmental and spirituality domains of life, and their intended goal post treatment. Most of the research on QoL post-bariatric surgery (20-23) has used the Short Form (SF)-36, a 36 item patientreported measure of well-being, with questions on physical functioning, role limitations due to physical or emotional problems, bodily pain, social functioning, and perceptions of general mental and physical health to give an overall mental health and physical health summary score.

Treatment-seeking individuals with obesity often present with depression and diminished HRQoL $(16,17)$. Depression, binge eating and diminished HRQoL has been reported to be higher for obese women (24). After bariatric surgery most patients report a greater improvement in psychosocial functioning and QoL (25). Improvements in well-being from baseline to 24 months post-surgery are reported regardless of type of surgery (20-23) and are generally in relation to physical rather than mental wellbeing (26). Increased well-being is associated with the amount of weight lost (21). In a study on five-year outcomes after LVSG (22) physical and mental SF-36 QoL was better at 5 years compared to baseline and BMI decreased from 46 to $32 \mathrm{~kg} / \mathrm{m}^{2}$. Sustained weight loss post-surgery requires food portion control, vitamin supplementation, physical activity and healthy eating. Where there is weight regain over time, this would be expected to impact on well-being.

\section{Bariatric surgery and body image}

Body image is defined as a multifaceted construct involving perceptual/evaluative aspects (body dissatisfaction), cognitive (appearance investment), affective (dysphoric emotions) and experiential aspects (body image QoL) $(27,28)$. Body image dissatisfaction (BID) is higher in the morbidly obese and is one of the motivating factors to undertake surgery (29). Pre-operative dissatisfaction with appearance has been linked to low self-esteem, depression and anxiety (30) and there is evidence that the effects of BID on psychological distress is mediated by emotional eating (30). Research (31) which has examined correlates of BID prior to surgery, 3 and 6 months post-bariatric surgery found that preoperative BID was associated with depressive symptoms, anxiety, low self-esteem and eating disorders. BID was also associated with psychopathology as measured by the Minnesota Multiphasic Personality Inventory (MMPI-2-RF) subscales of emotional/internalizing dysfunction, negative emotionality/neuroticism, self-doubt and low positive emotions. Those patients still experiencing BID 3 months post-surgery were more likely to have a depression diagnosis and elevated profile on the MMPI-2RF scales of demoralization, ideas of persecution, self-doubt and inefficacy. Six months post-surgery body dissatisfaction was also associated with emotional/internalization dysfunction, low self-esteem and anxiety.

Bariatric surgery patients demonstrate significant improvements in body image satisfaction and QoL in the first 2 years after surgery and these improvements are correlated with percentage of weight-loss (32). A recent study (33) found that body dissatisfaction, feelings of fatness and body image avoidance decreased at 1 and 6 months post-surgery. Diminished feelings of fatness correlated with 
Table 1 The number of persons having each type of bariatric surgery

\begin{tabular}{lcc}
\hline Type of surgery & N & $\%$ \\
\hline LRYGB & 29 & 20.4 \\
LAGB & 25 & 17.6 \\
LVSG & 87 & 61.3 \\
Intragastric balloon (gastric balloon) & 1 & 0.7 \\
\hline
\end{tabular}

LRYGB, laparoscopic Roux-en-Y gastric bypass; LAGB, laparoscopic adjustable gastric banding; LVSG, laparoscopic vertical sleeve gastrectomy.

the amount of weight lost at 6 months post-surgery but not at 1 month following surgery. One study (28) however did not find an association between BMI and body image variables of dysphoria, body image QoL, appearance satisfaction or appearance investment post-surgery. It is uncertain whether change in BMI may be a more sensitive indicator of body image satisfaction rather than BMI itself, which could explain the lack of an association between BMI and body image factors in the Ghai et al. (28) study.

Body image disturbance can also occur where the person still feels fat though they have lost significant amounts of weight. This is often referred to as a "mind-body lag" $(34,35)$ or an egocentric (personal experience of fatness) and allocentric (body as object incorporating beliefs and attitudes) disconnect $(36,37)$. Some individuals continue to feel dissatisfied with their body image after bariatric surgery. Dissatisfaction is most often related to the emergence of excess folds of skin where there has been substantial weight loss $(38,39)$. Some improvement in body dissatisfaction occurs with body contouring surgery $(39,40)$. Systematic reviews of the literature on body image following bariatric surgery generally indicate that there is improvement to some aspects of body image and subsequent QoL, though more research is needed on the multidimensional aspects which take into account perceptions, attitudes, emotional and behavioural features $(41,42)$.

The Aim of the study was to examine obesity HRQoL and body image satisfaction in a group of individuals having undergone bariatric surgery. The hypotheses were

(I) Individuals who have undergone bariatric surgery will have better obesity related QoL;

(II) Individuals who have had bariatric surgery will have high scores on the subscales of the Multidimensional Body Self-Relations Questionnaire (MBSRQ): Appearance Evaluation (AE); Appearance
Orientation (AO); Overweight Preoccupation (OP); Self-Classified Weight (SCW); Body Areas Satisfaction Scale (BASS);

(III) Obesity HRQoL, symptoms and subjective relevance of symptoms to well-being will be predicted by the change in BMI from before to after surgery, and body image variables of $\mathrm{AE}, \mathrm{AO}$, body areas satisfaction, OP and SCW.

\section{Methods}

\section{Participants}

One hundred and forty-two persons who had undergone bariatric surgery answered an online survey which included measures of well-being and body image. Another 70 persons who met the criteria for obesity but had not received surgery also answered the online survey. Information was collected on gender, age, type of surgery, previous and current weight $(\mathrm{kg})$ and height (meters) to calculate BMI. The average age of respondents was 43 years. The sample was predominantly female (88\%). Most of the respondents had received the surgery in the last 10 years. The current BMI for the sample was $32.6 \mathrm{~kg} / \mathrm{m}^{2}$. Table 1 presents the number of persons who had received each type of bariatric surgery. Most of the sample had received the LVSG (61.3\%) with LRYGB (20.4\%) being the next type of surgery with the largest percentage of patients. The average heaviest weight before surgery was $133 \mathrm{~kg}$ and current weight was $98 \mathrm{~kg}$. The mean BMI change from before to after weight loss surgery was $10.83 \mathrm{~kg} / \mathrm{m}^{2}$.

\section{Measures}

\section{Orwell 97}

The obesity-related well-Being scale is a self-reported measure of obesity-related QoL. The questionnaire considers both the intensity and subjective relevance of physical and psychosocial distress (43). There are 18 questions consisting of two parts. It uses a 4-point Likert scale ranging from not at all [0] to much [3]. Well-being is determined by the participants' responses to questions that assess occurrence of the symptoms (O: occurrence) and the relevance of said symptoms to their lives (R: relevance). Scores can be summed across items to obtain a total symptoms occurrence score and summing across items relating to relevance gives a total relevance score. The sum of items assessing occurrence weighted for relevance to 
well-being provides the total Orwell 97 score. High scores on the Orwell 97 indicate lower obesity-related well-being while low scores indicate higher well-being (43). Cronbach's alpha for the overall Orwell 97 was 0.90 , for the symptom occurrence subscale $\alpha$ was 0.72 , and for the symptom relevance subscale was 0.89 , indicating that the Orwell 97 is a very reliable assessment of obesity related well-being.

Sample item:

* O: Does being overweight interfere with your opinion of yourself?

* R: Do you have a negative opinion of yourself?

\section{MBSRQ-Appearance Scales (MBSRQ-AS) 34}

The MBSRQ-AS 34 is the shortened version of the 69 item MBSRQ attitudinal body image assessment. The measure uses a 5 -point response format ranging from 1 definitely disagree to 5 definitely agree $(44,45)$. This study used all 5 of the MBSRQ-AS 34 subscales: AE, AO, OP, SCW, BASS. The MBSRQ-AS 34 has been used in studies of obesity without surgery, before and after bariatric surgery $(40,46,47)$. AE is a 7 -item measure of satisfaction with attractiveness, and positive or negative selfperceptions of physical appearance. High scores indicate positive and satisfied perceptions of physical appearance and attractiveness. $\mathrm{AO}$ is a 12 -item measure of personal investment in grooming and appearance presentation. High scores indicate high levels of attention to appearance and extensive grooming. OP is a four-item measure of fat anxiety, weight vigilance, dieting and eating restraint. High scores indicate high fat anxiety and high levels of dieting behaviour. SCW consists of two items that indicate the individual's perception of their weight-"I think I am" and label of their weight "others say I am". The scale ranges from 1-very underweight to 5-very overweight. High scores indicate a high subjective and internalized perception of self as obese, whilst low scores indicate a high subjective and internalized view of self as thin. The BASS is a 9-item scale that measures the degree of dissatisfaction or satisfaction with specific body areas and attributes (e.g., face, weight, muscle tone, etc.), where high scores indicate an overall satisfaction with subjective body appearance, whilst low scores indicate an overall dissatisfaction with subjective body appearance. Cronbach alphas in the current study were 0.87 (AE), $0.86(\mathrm{AO}), 0.55(\mathrm{OP}), 0.89$ (SCW), and 0.81 (BASS), confirming the MBSRQ-AS 34 as a reliable measure of body image.

Statistical analysis
$T$-test analyses were used to compare persons who had undergone bariatric surgery to those who had not received surgery on measures of well-being and body image. Pearson correlation was used to assess the relationship between BMI, obesity related well-being and body image. Hierarchical multiple regression was used to assess the predictive effect of BMI change following surgery on well-being, controlling for body image perceptions.

\section{Results}

An independent samples $t$-test was used to test Hypothesis 1 that compared to persons who had not undergone bariatric surgery, those who had received surgery would have a better obesity-related QoL (total Orwell 97 scores, less symptoms, less reported relevance of symptoms to well-being). There were no significant t-test results when any of the three wellbeing dependent variables were investigated. Those who had received surgery were not experiencing better wellbeing compared to those who had not received surgery.

To test Hypothesis 2, $t$-tests were computed for each of the MBSRQ-AS 34 subscales for those who had received versus had not undergone bariatric surgery. The only significant result was for the OP subscale $t(116)=4.56$, $\mathrm{P}<0.01$. Those who had received surgery were more preoccupied with weight (mean $=4.0, \mathrm{SD}=0.76$ ) compared to those who had not received surgery (mean $=3.14$, $\mathrm{SD}=0.94)$.

Overall obesity-related well-being was correlated $(-0.26$, $\mathrm{P}<0.01)$ with change in BMI. Body image subscales also correlated significantly with overall well-being with the exception of the AO subscale of the MBSRQ-AS 34. Wellbeing correlated with $\mathrm{AE}(r=-0.59, \mathrm{P}<0.001)$, body areas satisfaction $(r=-0.67, \mathrm{P}<0.001)$, weight preoccupation $(r=0.54, \mathrm{P}<0.001)$ and SCW $(r=0.54, \mathrm{P}<0.001)$. Descriptive statistics on key variables for the whole sample are found in Table 2. Those persons who were satisfied with specific bodily areas and with their overall attractiveness, and had positive perceptions of physical appearance following surgery reported the highest well-being. Those who were still preoccupied with their weight and who still regarded themselves as obese reported diminished well-being.

Hierarchical multiple regression was used to assess the predictive ability of change in BMI following bariatric surgery, along with the body-image subscales of the MBSRQ-AS 34 to predict overall well-being of patients (Hypothesis 3). The regression analysis was based on 
Table 2 Descriptive statistics for major variables

\begin{tabular}{lcc}
\hline Variables & Mean & Standard deviation \\
\hline BMI change & 10.83 & 7.73 \\
Appearance evaluation & 2.49 & 0.92 \\
Appearance orientation & 3.42 & 0.62 \\
Body areas satisfaction & 2.72 & 0.73 \\
Weight preoccupation & 3.72 & 0.78 \\
Self-classified weight & 4.21 & 0.72 \\
Orwell97 & 46.38 & 27.07 \\
Symptom occurrence & 29.63 & 6.77 \\
Symptom relevance & 23.0 & 10.97 \\
\hline
\end{tabular}

91 persons who had complete data across all variables (see Table 3 for the results of these regression analyses). When the dependent variable was total obesity-related well-being as measured by the Orwell 97, change in BMI $(B=-0.273)$ explained $6.8 \%$ of the variance in well-being $[F(1,89)$ $=6.479, \mathrm{P}<0.05]$. At Step 2 of the regression adding the body image subscales, an additional $50.2 \%$ of the variance was explained $[F(6,84)=18.54, \mathrm{P}<0.01]$. Of the body image variables, the strongest predictor was body areas satisfaction $(B=-0.360, \mathrm{P}<0.01)$, indicating that patients who were satisfied with how different areas of their body looked following surgery had better well-being. SCW and weight preoccupation were equally predictive of wellbeing $(B=0.295, \mathrm{P}<0.01)$ indicating that those who were still preoccupied with their weight, and had an internalized perception of self as obese, had lower well-being (high scores on the Orwell 97 indicate lower well-being). Interestingly at Step 2 when the body image variables were entered, change in BMI $(B=0.001)$ no longer predicted wellbeing, demonstrating the importance of subjective body image over a physical parameter (actual weight lost) in influencing well-being.

When the occurrence of symptoms subscale of the Orwell 97 was the dependent variable, change in BMI at Step 1 did not significantly predict symptoms. At Step 2 (see Table 3) when the body image variables were entered, the regression was significant, $F(6,84)=10.543, \mathrm{P}<0.001$ ) and explained $43 \%$ of the variance. The best predictor of symptom occurrence was body areas satisfaction $(B=-0.327$, $\mathrm{P}<0.05)$, followed by SCW $(B=0.206, \mathrm{P}<0.05)$. Those persons who were satisfied with the changes to body areas following surgery had the better obesity-related well-being, whereas those who still perceived themselves as overweight reported more symptoms which impacted on well-being.

When the subjective relevance of symptoms for wellbeing was the dependent variable $59.5 \%$ of the variance was explained by body image variables $[F(6,84)=20.54, \mathrm{P}<0.001]$ (refer to Table 3). Change in BMI while significant at Step 1 of the regression $(B=-0.289, \mathrm{P}<0.01)$ became non-significant at Step 2. The best predictor of symptom relevance at Step 2 was SCW $(B=0.328, \mathrm{P}<0.01)$, followed by body areas satisfaction $(B=-0.320, \mathrm{P}<0.01)$ and $\mathrm{OP}(B=0.292, \mathrm{P}<0.01)$. If the person was still preoccupied with their weight postsurgery, and classified themselves as still being obese they gave a higher endorsement of the subjective relevance of symptoms for well-being. If they were satisfied with different areas of their body, then they perceived the symptoms as having less relevance to their obesity-related well-being.

As the majority of patients $(61.3 \%)$ had received the LVSG, the data was next analysed for this group to assess the variables which had the most impact on obesity-related well-being. Hypothesis 3 was therefore tested for the LVSG group with overall well-being, symptom occurrence and subjective relevance of symptoms as the dependent variables in three separate regressions. There were 63 persons who had received the LVSG. The first hierarchical regression considered overall well-being for those who received the LVSG. The results of this regression are reported in Table 4. At Step 2 of the regression when change in BMI and body image variables were entered, the amount of variance explained in total obesity-related well-being was $52 \%$. The ANOVA was significant at the 0.0001 level $[F(6,56)=10.16]$. For the LVSG group, satisfaction with different body areas was the best predictor of well-being $(B=-0.365, \mathrm{P}<0.05)$, followed by OP $(B=0.313, \mathrm{P}<0.05)$ and SCW $(B=0.281$, $\mathrm{P}<0.05)$. Being satisfied with bodily areas was associated with better overall well-being, while weight preoccupation and classifying oneself as still overweight were associated with diminished well-being.

When the dependent variable was symptom occurrence $40.7 \%$ of the variance was explained by a combination of $\mathrm{BMI}$ weight change and body image variables $[F(6,56)$ $=6.39, \mathrm{P}<0.01]$. OP $(B=0.311, \mathrm{P}<0.05)$ and SCW $(B=0.279$, $\mathrm{P}<0.05)$ were associated with more symptoms which impacted on well-being. The results of this regression appear in Table 4.

When the dependent variable was symptom relevance, at Step 1 of the hierarchical regression, change in BMI $(B=-0.298, \mathrm{P}<0.05)$ as a result of the LVSG significantly 
Table 3 Hierarchical regressions predicting obesity-related well-being, symptom occurrence and relevance of symptoms from change in BMI and body image subscales $(\mathrm{N}=91)$

\begin{tabular}{|c|c|c|c|c|c|c|c|}
\hline Dependent variable & Predictors (Step 2) & $B$ & Std. Error & Beta & $\mathrm{R}^{2}$ & \multicolumn{2}{|c|}{ Confidence interval } \\
\hline \multirow[t]{5}{*}{ Orwell 97} & Change in BMI & 0.002 & 0.108 & 0.001 & 0.570 & -0.213 & 0.217 \\
\hline & Appearance evaluation & -0.340 & 3.836 & -0.012 & & -7.967 & 7.288 \\
\hline & Appearance orientation & -1.316 & 3.589 & -0.030 & & -8.452 & 5.820 \\
\hline & Overweight preoccupation & 10.143 & 3.245 & $0.295^{\star *}$ & & 3.690 & 16.597 \\
\hline & Self-classified weight & 10.997 & 3.286 & $0.295^{\star *}$ & & 4.462 & 17.531 \\
\hline \multirow[t]{4}{*}{ Occurrence of symptoms } & Change in BMI & 0.011 & 0.031 & 0.033 & 0.430 & -0.051 & 0.073 \\
\hline & Appearance evaluation & -0.624 & 1.106 & -0.085 & & -2.822 & 1.575 \\
\hline & Overweight preoccupation & 1.803 & 0.935 & $0.209^{*}$ & & -0.058 & 3.663 \\
\hline & Self-classified weight & 1.921 & 0.947 & $0.206^{*}$ & & 0.038 & 3.805 \\
\hline \multirow[t]{6}{*}{ Relevance of symptoms } & Change in BMI & -0.014 & 0.043 & -0.025 & 0.595 & -0.099 & 0.070 \\
\hline & Appearance evaluation & -0.435 & 1.509 & -0.037 & & -3.435 & 2.565 \\
\hline & Appearance orientation & 0.037 & 1.412 & 0.002 & & -2.770 & 2.844 \\
\hline & Body areas satisfaction & -4.785 & 1.916 & $-0.320^{\star \star}$ & & -8.594 & -0.975 \\
\hline & Overweight preoccupation & 4.074 & 1.276 & $0.292^{\star \star}$ & & 1.536 & 6.613 \\
\hline & Self-classified weight & 4.948 & 1.292 & $0.328^{\star \star}$ & & 2.378 & 7.518 \\
\hline
\end{tabular}

${ }^{*}, \mathrm{P}<0.05 ;{ }^{* *}, \mathrm{P}<0.01$. BMI, body mass index.

impacted on well-being as measured by the Orwell $97[F(1,61)=5.94, \mathrm{P}<0.05]$, explaining $8.9 \%$ of the variance. At Step 2 when the body image variables were entered, the impact of weight change became non-significant $(B=-0.079)$ being overshadowed by body image perceptions $[F(6,56)$ $=11.73, \mathrm{P}<0.001]$. The amount of variance explained increased to $55.7 \%$ with the addition of body image variables. The most significant predictors of symptom relevance were body areas satisfaction $(B=-0.318, \mathrm{P}<0.05)$ followed by SCW $(B=0.314, \mathrm{P}<0.05)$, and $\mathrm{OP}(B=0.260$, $\mathrm{P}<0.05)$. Table 4 presents the results of this regression.

\section{Discussion}

Bariatric surgery for the morbid obese is the recommended weight loss method. The participants in this study had lost on average $35 \mathrm{~kg}$ since their surgery. This would seem to suggest that BMI change would predict obesity- related well-being for our participants. Results of the hierarchical regressions indicated that both for the overall sample of surgical patients, and for the gastric sleeve patients, body image factors were even more important predictors for well-being than weight lost. Psychological factors such as the perception of body areas, continued weight preoccupation and SCW rather than objective weight were better predictors of well-being, symptoms that impacted on well-being and on the subjective relevance of the symptoms to well-being. While the regression for BMI change (Step 1) was significant for the total sample when overall well-being was the dependent variable, and significant for both the overall sample and for the gastric sleeve sample when symptom relevance was the dependent variable, its effect was reduced to non-significance when the body image variables were entered at Step 2 of all the hierarchical regression analyses. Therefore, there was mixed support for Hypothesis 3. Research has generally indicated 
Table 4 Hierarchical regressions predicting obesity-related well-being, symptom occurrence and relevance of symptoms from change in BMI and body image subscales for the gastric sleeve group $(\mathrm{N}=63)$

\begin{tabular}{|c|c|c|c|c|c|c|c|}
\hline Dependent variable & Predictors (Step 2) & $B$ & Std. Error & Beta & $\mathrm{R}^{2}$ & \multicolumn{2}{|c|}{ Confidence interval } \\
\hline \multirow[t]{5}{*}{ Orwell 97} & Change in BMI & -0.020 & 0.125 & -0.017 & 0.521 & -0.271 & 0.230 \\
\hline & Appearance evaluation & 1.519 & 4.435 & 0.057 & & -7.366 & 10.403 \\
\hline & Appearance orientation & -0.205 & 4.124 & -0.005 & & -8.465 & 8.056 \\
\hline & Overweight preoccupation & 10.414 & 4.125 & $0.313^{*}$ & & 2.150 & 18.678 \\
\hline & Self-classified weight & 10.115 & 4.469 & $0.281^{\star}$ & & 1.163 & 19.068 \\
\hline \multirow[t]{4}{*}{ Occurrence of symptoms } & Change in BMI & 0.018 & 0.037 & 0.057 & 0.407 & -0.055 & 0.092 \\
\hline & Appearance evaluation & 0.166 & 1.300 & 0.024 & & -2.438 & 2.770 \\
\hline & Overweight preoccupation & 2.722 & 1.209 & $0.311^{*}$ & & 0.300 & 5.144 \\
\hline & Self-classified weight & 2.639 & 1.310 & $0.279^{\star}$ & & 0.015 & 5.263 \\
\hline \multirow[t]{6}{*}{ Relevance of symptoms } & Change in BMI & -0.038 & 0.048 & -0.079 & 0.557 & -0.134 & 0.057 \\
\hline & Appearance evaluation & -0.138 & 1.695 & -0.013 & & -3.534 & 3.258 \\
\hline & Appearance orientation & 0.968 & 1.576 & 0.063 & & -2.190 & 4.125 \\
\hline & Body areas satisfaction & -4.362 & 2.270 & $-0.318^{*}$ & & -8.910 & 0.185 \\
\hline & Overweight preoccupation & 3.432 & 1.577 & $0.260^{*}$ & & 0.273 & 6.591 \\
\hline & Self-classified weight & 4.495 & 1.708 & $0.314^{*}$ & & 1.073 & 7.917 \\
\hline
\end{tabular}

*, $\mathrm{P}<0.05 ;{ }^{* \star}, \mathrm{P}<0.01$. BMI, body mass index.

improved well-being post-surgery to be associated with the amount of weight lost $(21,22,33)$. Systematic reviews have reported mixed evidence for the association between weight outcomes and post-operative body image (41). Some research (47) has found $\mathrm{BMI}$ to be related to $\mathrm{AE}$ but not AO. Other research has not found an association between BMI and body image dysphoria, QoL, appearance satisfaction or appearance investment (28). This would seem to indicate that post-operative weight loss alone is insufficient for obesity-related well-being and that body image concerns need to be addressed in patients as part of post-surgical care.

When we examine bivariate correlations, the subscale $\mathrm{AE}$ was highly correlated with well-being. However, in the hierarchical regressions, the $\mathrm{AE}$ subscale did not predict any of the well-being variables. Subjective perceptions of body image nevertheless were important determinants of wellbeing for the overall sample and for the vertical sleeve group with body areas satisfaction, OP and SCW consistently predicting all three measures of well-being: overall wellbeing, symptom occurrence and symptom relevance. Earlier research (28) also found a positive correlation between QoL and satisfaction with one's appearance as measured by the AE subscale of the MBSRQ-AS 34.

Contrary to the prediction of Hypothesis 1, persons who had undergone bariatric surgery did not have better obesityrelated QoL compared to those still awaiting surgery. The current findings of better QoL for those who were still to undergo bariatric surgery do not support previous research $(20,22,23,25)$. However, these earlier studies assessed well being for the bariatric patients using a different measure (SF-36) to the current study which used the Orwell 97 an obesity specific measure of well-being. Moreover, these previous studies did not use a comparison group of nonsurgical persons.

There was only minimal support for Hypothesis 2. Of 
the MBSRQ-AS 34 subscales assessing body image, only the weight preoccupation subscale evidenced mean differences between persons who had received surgery and those who had not. Those persons who had not undergone surgery had less weight preoccupation compared to those who had received the surgery. Research (29) generally indicates that perceiving oneself as overweight or obese is a motivating factor for having surgery. Perhaps the continued weight concerns for the current sample could be due to patients' unmet expectations in relation to the amount of weight lost following surgery. There is some evidence in the literature (48) for patients to overestimate the amount of weight they will lose compared to the estimates of their surgeon.

\section{Limitations}

One of the limitations of the current study is that respondents were at different timeframes since surgery. Some respondents may have had their surgery 10 years ago while others may have had their surgery recently. This may explain why some persons had a higher BMI than others as there may have been some weight regain over longer periods of time which would impact on body image evaluations and subsequently on well-being.

There were a greater number of females to males in this sample however this reflects the statistics on obesity and gender ratio of persons having bariatric surgery (3). Future research on a male obese sample would be recommended.

\section{Recommendations for translating research on body image to practice}

A number of recommendations for the translation of the present research findings for the surgical preparation of the bariatric patient and for post-surgery care are suggested. Given the research evidence for body image disturbance pre-surgery having carry over effects postsurgery (31), body image assessment should be part of presurgery screening. In addition to assessment of body image, assessment of psychopathology in particular depression, anxiety and disordered eating pathology should be assessed prior to surgery.

Systematic reviews $(41,42)$ have emphasised the multidimensional nature of body image and as such cognitive, perceptual, emotional and behavioural aspects should be assessed. A number of measures for the assessment of body image in relation to body attitude, body checking, $\mathrm{AO}$ and perceived size have been offered in the literature (49) though these instruments were not developed specifically for obese persons and have not been validated for use with bariatric patients. More recently measures specific to the bariatric surgery patient such as the BODY-Q have been developed and are highly recommended for use in assessment of body image disturbance following surgery as items tap into concerns relating to excess skin after surgery, and attitudes to body contouring (50). Pre-surgical assessment of body image motivations for surgery may also provide information on unrealistic patient expectations of weight loss following surgery which should be targeted for psychoeducation.

The mind-body lag (36) or lack of egocentric-allocentric congruence (37) has been reported in the literature and was also confirmed in the current study. OP and subjective perceptions of weight rather than objective weight indicators predicted obesity-related well-being in the current study. Consistent with the findings of systematic reviews (42). satisfaction with body areas following surgery was associated with better well-being. Despite substantial weight loss, some individuals still perceive themselves to be obese and as a consequence experience diminished wellbeing. Weight loss maintenance is more likely when the patient is experiencing physical and mental well-being. Some individuals who have been overweight or obese most of their lives define themselves by their weight and have come to identify themselves with this larger body frame. Subsequently, they may not be able to relate to the image of themselves reflected back in the mirror. Assessment of body dysmorphia post-surgery is critical to identifying individuals who will have difficulty adjusting to their new image of themselves and who may require psychological counselling or therapeutic intervention. Post-surgical care of the bariatric patient should also incorporate positive aspects of body image such as body functionality (e.g., better mobility, greater energy), improved health, and reduced comorbidities, rather than purely aesthetic ones.

The current research has added to the body of literature on body image and well-being of the bariatric patient. The findings support previous systematic reviews on body image disturbance in patients following bariatric surgery despite significant weight loss. In the translational research continuum, evidence exists for the importance of body image assessment both pre-surgery and as part of postsurgical care and monitoring. Psychological support for the mental health needs of obese patients post-surgery has been advocated in the literature (51). Future research needs 
to examine the effectiveness and efficacy of implementing psychosocial assessment and counselling as part of health care delivery for the bariatric patient so that clinical guidelines can be established.

\section{Acknowledgments}

I wish to acknowledge Sheena Smith, Ashley Ristanto and Madeline Martin who collected the data for this project.

Funding: None.

\section{Footnote}

Provenance and Peer Review: This article was commissioned by the Guest Editor (Muhammed Ashraf Memon) for the focused issue "Bariatric Surgery" published in Annals of Translational Medicine. The article was sent for external peer review organized by the Guest Editor and the editorial office.

Conflicts of Interest: The focused issue "Bariatric Surgery" was commissioned by the editorial office without any funding or sponsorship. The author has no conflicts of interest to declare.

Ethical Statement: The author is accountable for all aspects of the work in ensuring that questions related to the accuracy or integrity of any part of the work are appropriately investigated and resolved. This study was approved by the Human Research Ethics Committee of James Cook University (approval ID H6584).

Open Access Statement: This is an Open Access article distributed in accordance with the Creative Commons Attribution-NonCommercial-NoDerivs 4.0 International License (CC BY-NC-ND 4.0), which permits the noncommercial replication and distribution of the article with the strict proviso that no changes or edits are made and the original work is properly cited (including links to both the formal publication through the relevant DOI and the license). See: https://creativecommons.org/licenses/by-nc-nd/4.0/.

\section{References}

1. Titler MG. Overview of the U.S. invitational conference "Advancing Quality Care through Translation Research". Worldviews Evid Based Nurs 2004;1 Suppl 1:S1-5.

2. AIHW: Australian Institute of Health and Welfare.
Overweight and obesity. Accessed online on 28th Nov. Available online: https://www.aihw.gov.au/reports-data/ behaviours-risk-factors/overweight-obesity/overview

3. AIHW: Australian Institute of Health and Welfare. Weight loss surgery in Australia 2014-15: Australian hospital statistics. Cat. no. HSE 186. Canberra: AIHW, 2017.

4. Picot J, Jones J, Colquitt JL, et al. The clinical effectiveness and cost-effectiveness of bariatric (weight loss) surgery for obesity: a systematic review and economic evaluation. Health Technol Assess 2009;13:1-190, 215-357, iii-iv.

5. Saunders TJ, Tremblay MS, Després JP, et al. Sedentary Behaviour, Visceral Fat Accumulation and Cardiometabolic Risk in Adults: A 6-Year Longitudinal Study from the Quebec Family Study. PLoS One 2013;8:e54225.

6. Sjöström L. Review of the key results from the Swedish Obese Subjects (SOS) trial - a prospective controlled intervention study of bariatric surgery. J Intern Med 2013;273:219-34.

7. Magro DO, Geloneze B, Delfini R, et al. Long-term Weight Regain after Gastric Bypass: A 5-year Prospective Study. Obes Surg 2008;18:648-51.

8. Lager CJ, Esfandiari NH, Subauste AR, et al., Milestone weight loss goals (Weight normalization and emission of obesity) after gastric bypass surgery: Long term results from the University of Michigan. Obes Surg 2017;27:1659-66.

9. Topart P, Becouarn G, Delarue J. Weight loss and nutritional outcomes 10 years after biliopancreatic diversion with duodenal switch. Obes Surg 2017;27:1645-50.

10. Kowalewski PK, Olszewski R, Kwiatkowski A, et al. Life with a Gastric Band. Long-Term Outcomes of Laparoscopic Adjustable Gastric Banding-a Retrospective Study. Obes Surg 2017;27:1250-3.

11. Bittner JG, Clingempeel NL, Wolf LG. Weight loss failure and reoperation after laparoscopic adjustable gastric banding and gastric bypass: A case-matched cohort study. Obes Surg 2017;27:2885-9.

12. Monaco-Ferreira DV, Leandro-Merhi VA. Weight regain 10 years after Roux-en-Y gastric bypass. Obes Surg 2017;27:1137-44.

13. Arapis K, Tammaro P, Parenti R. et al. Long-term results after Laparoscopic adjustable gastric banding for morbid obesity: 18 year follow-up in a single University unit. Obes Surg 2017;27:630-40.

14. Adami GF, Scopinaro N, Cordera R. Adipokine Pattern After Bariatric Surgery: Beyond the Weight Loss. Obes Surg 2016;26:2793-801. 
15. Yang J, Feng X, Zhong S, et al. Gastric Bypass Surgery May Improve Beta Cell Apoptosis with Ghrelin Overexpression in Patients with $\mathrm{BMI} \geq 32.5 \mathrm{~kg} / \mathrm{m}^{2}$. Obes Surg 2014;24:561-71.

16. Dawes AJ, Maggard-Gibbons M, Maher AR, et al. Mental health conditions among patients seeking and undergoing bariatric surgery: A meta-analysis. JAMA 2016;315:150-63.

17. Miras AD, Al-Njim, W, Jackson SN, et al. Psychological characteristics, eating behavior, and quality of life assessment of obese patients undergoing weight loss interventions Scand J Surg 2015;104:10-7.

18. Diener E. Guidelines for national indicators of subjective well-being and ill-being. Appl Res Qual Life 2006;1:151-7.

19. World Health Organization (WHO, 2019) WHOQOL: Measuring quality of life. Accessed 17 May, 2019. Available online: https://www.who.int/healthinfo/survey/whoqolqualityoflife/en/

20. Biter LU, van Buuren MM, Mannaerts GH, et al. Quality of life 1 year after laparoscopic sleee gastrectomy versus laparoscopic roux-en-Y gastric bypass: a randomized controlled trial focusing on gastroesophageal reflux disease. Obes Surg 2017;27:2557-65.

21. Monpellier VM, Antoniou EE, Aarts EO, et al. Improvement of health-related quality of life after Rouxen-Y Gastric bypass related with weight loss. Obes Surg 2017;27:1168-73.

22. Flølo TN, Andersen JR, Kolotkin RL, et al. FiveYear Outcomes After Vertical Sleeve Gastrectomy for Severe Obesity: A Prospective Cohort Study. Obes Surg 2017;27:1944-51.

23. Porta A, Aiolfi A, Musolino C, et al. Prospective comparison and quality of life for single-incision and conventional laparoscopic sleeve gastrectomy in a series of morbidly obese patients. Obes Surg 2017;27:681-7.

24. Marzocchi R, Moscatiello S, Villanova N, et al. Psychological Profile and Quality of Life of Morbid Obese Patients Attending a Cognitive Behavioural Program. Psychological Topics 2008;17:349-60.

25. Laurino Neto RM, Herbella FA. Changes in quality of life after short and long term follow-up of Roux-en-Y gastric bypass for morbid obesity. Arq Gastroenterol 2013;50:186-90.

26. Lindekilde N, Gladstone BP, Lubeck M, et al. The impact of bariatric surgery on quality of life: a systematic review and meta-analysis. Obes Rev 2015;16:639-51.

27. Cash TF. Crucial considerations in the assessment of body image. In: Cash TF, Smolak L. editors, Body image: A Handbook of Science Practice, and Prevention. New York,
Guiford Press, 2011:129-37.

28. Ghai A, Milosevic I, Laliberte M, et al. Body image concerns in obese women seeking bariatric surgery. Ethnic Inequal Health Soc Care 2014;7:96-107.

29. Libeton M, Dixon JB, Laurie C, et al. Patient motivation for bariatric surgery: characteristics and impact on outcomes. Obes Surg 2004;14:392-8.

30. Geller S, Levy S, Goldzweig G, et al. Psychological distress among bariatric surgery candidates: The roles of body image and emotional eating. Clin Obes 2019;9:e12298.

31. Pona AA, Marek RJ, Heinberg LJ, et al. Psychological correlates of body image dissatisfaction before and after bariatric surgery. Bariatr Surg Pract Patient Care 2017;12:184-9.

32. Sarwer DB, Wadden TA, Moore RH, et al. Changes in quality of life and body image after gastric bypass surgery. Surg Obes Relat Dis 2010;6:608-14.

33. Williams GA, Hudson DL, Whisenhunt BL, et al. Shortterm changes in affective, behavioural and cognitive components of body image after bariatric surgery. Surg Obes Relat Dis 2018;14:521-6.

34. Alegría CA, Larsen B. "That's who I am: a fat person in a thin body": weight loss, negative self-evaluation, and mitigating strategies following weight loss surgery. J Am Assoc Nurse Pract 2015;27:137-44.

35. Faccio E, Nardin A, Cipolletta S. Becoming ex-obese: Narrations about identity changes before and after the experience of the bariatric surgery. J Clin Nurs 2016;25:1713-20.

36. Riva G. Neuroscience and eating disorders: The allocentric lock hypothesis. Med Hypotheses 2012;78:254-7.

37. Perdue TO, Schreier A, Neil J, et al. A Concept Analysis of Disturbed Body Image in Bariatric Surgery Patients. Int J Nurs Knowl 2020;31:74-81.

38. Song AY, Rubin JP, Thomas V, et al. Body Image and Quality of Life in Post Massive Weight Loss Body Contouring Patients. Obesity 2006;14:1626-36.

39. Pecori L, Cervetti G, Marinari GM, et al. Attitudes of morbidly obese patients to weight loss and body image following bariatric surgery and body contouring. Obes Surg 2007;17:68-73.

40. de Zwaan M, Georgiadou E, Stroh CE, et al. Body image and quality of life in patients with and without body contouring surgery following bariatric surgery: a comparison of pre- and post-surgery groups. Front Psychol 2014;5:1310.

41. Ivezaj V, Grilo CM. The complexity of body image 
following bariatric surgery: A systematic review of the literature. Obes Rev 2018;19:1116-40.

42. Bertoletti J, Aparicio MJ, Bordignon S, et al. Body image and bariatric surgery: A systematic review of literature. Bariatr Surg Pract Patient Care 2018;14:81-92.

43. Mannucci E, Ricca V, Barciulli E, et al. Quality of life and overweight: The obesity related well-being (Orwell 97) Questionnaire. Addict Behav 1999;24:345-57.

44. Brown TA, Cash TF, Mikulka PJ. Attitudinal Body-Image Assessment: Factor analysis of the Body-Self Relations Questionnaire. J Pers Assess 1990;55:135-44.

45. Cash TF, Morrow JA, Hrabosky JI, et al. How has body image changed? A cross-sectional investigation of college women and men from 1983 to 2001. J Consult Clin Psychol 2004;72:1081-9.

46. Carels RA, Burmeister, J, Oehlhof M, et al. Internalized weight bias: ratings of the self, normal weight, and obese individuals and psychological maladjustment. J Behav Med 2013;36:86-94.

Cite this article as: Caltabiano ML. Translational aspects of body image research for obesity-related quality of life and weight loss maintenance post-bariatric surgery. Ann Transl Med 2020;8(Suppl 1):S2. doi: 10.21037/atm.2019.09.63
47. Dixon JB, Dixon ME, O'Brien PE. Body image: appearance orientation and evaluation in the severely obese. Changes with weight loss. Obes Surg 2002;12:65-71.

48. Price HI, Gregory DM, Twells LK. Body shape expectations and self-ideal body shape discrepancy in women seeking bariatric surgery: a cross-sectional study. BMC Obes 2014;1:28.

49. Varns JA, Fish AF, Eagon C. Conceptualization of body image in the bariatric surgery patient. Appl Nurs Res 2018;41:52-8.

50. Klassen AF, Cano SJ, Alderman A, et al. The BODY-Q: A patient-reported outcome instrument for weight loss and body contouring treatments. Plast Reconstr Surg Glob Open 2016;4:e679.

51. Ristanto A, Caltabiano ML. Psychological Support and Well-being in Post-Bariatric Surgery Patients. Obes Surg 2019;29:739-43. 